\title{
POI-02. Anti-inflammatory and regulatory mechanisms provide the context for an effective CD8+ $T$ cell response in live-attenuated immunized animals
}

\author{
M Genescà Ferrer*, M Ma, J Li, L Fritts, MB McChesney and CJ Miller
}

Address: Virology \& Immunology, UC Davis - CNPRC/CCM, Davis, CA, USA

* Corresponding author

from AIDS Vaccine 2009

Paris, France. 19-22 October 2009

Published: 22 October 2009

Retrovirology 2009, 6(Suppl 3):P2 doi:10.1 186/I 742-4690-6-S3-P2

This abstract is available from: http://www.retrovirology.com/content/6/S3/P2

(c) 2009 Ferrer et al; licensee BioMed Central Ltd.

\section{Background}

Live, attenuated SHIV89.6 immunization protects macaques against vaginal challenge with SIVmac239. SIVspecific effector/memory CD8+ T cells, present in the vagina at the time of challenge, mediate this protection and they do not expand dramatically after challenge. Thus, we hypothesized that the persistent, low-level replication of vaccine virus induces regulatory mechanisms which maintain a controlled, inflammatory environment that does not promote viral replication.

\section{Methods}

We assessed CD4+ and CD8+ T regulatory cell frequencies in the tissues of immunized and unimmunized rhesus macaques and gene expression of pro-inflammatory and regulatory molecules before and after SIVmac239 vaginal challenge.

\section{Results}

On the day of challenge, the frequency of circulating $\mathrm{CD} 4+\mathrm{T}$ regulatory cells was significantly lower in the immunized monkeys than in normal controls. However, after challenge (PC), these cells expanded more rapidly and strongly in lymph nodes (LN) of the immunized macaques compared to the control macaques. In addition, at 3 days PC, the frequency of vaginal mucosal CD4+FoxP3+ cells increased in the immunized macaques $(\mathrm{p}<0.05)$. In contrast, the frequencies of CD8+FoxP3+ T cells in tissues of immunized macaques did not increase $\mathrm{PC}$, as they did in control monkeys. Differences in expres- sion of pro-inflammatory and regulatory genes were detected in the immunized macaques compared to gene expression in normal, uninfected macaques at the time of challenge. IL-8, IL-17, CCL3 and TNF mRNA levels were significantly decreased in LNs and/or vagina of immunized macaques. IL-17 mRNA was up-regulated at the site of challenge on day 7 PC while in SHIV-immunized macaques it was down-regulated $(p=0.017)$. Finally, IL-6 increased over-time in tissues of the control, but not the immunized macaques PC.

\section{Conclusion}

Protection from vaginal challenge in SHIV-immunized macaques was associated with expansion of $\mathrm{T}$ regulatory cells in tissues but not in blood and down-regulation of inflammatory molecules, before and immediately after challenge. 